\title{
QK73
}

.B74

G33

Gager, Charles Stuart

The Brooklyn botanic garden 




\title{
The Brooklyn Botanic Garden
}

\author{
By C. Stuart Gager, Director
}

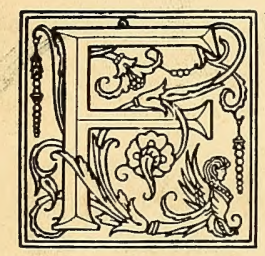

EW American cities have botanic gardens. This is in marked contrast to Europe, where nearly every city of any considerable size has a botanic garden, either as a separate institution or as a department of the local university. In the United States a number of colleges and universities maintain gardens in connection with their botanical departments. Such, for example, is the case at Harvard, the University of Pennsylvania, Smith, Mt. Holyoke, Michigan Agricultural College, and the University of Mighigan. With the exception of such gardens, and also excepting the Arnold Arboretum at Jamaica Plain, near Boston, and the Letchworth Park Arboretum along both sides of the Genesee River in New York, both devoted exclusively to trees and shrubs, there are now only three independent botanic gardens in the United States, namely the Missouri Botanical Garden, at St. Louis, the New York Botanical Garden, in Bronx Borough, and the Brooklyn Botanic Garden. Of the last three, the Brooklyn garden is the youngest, having been established in 1910 .

Like several other educational institutions in New York City, the Brooklyn Botanic Garden is administered by a private organization (in this case the Brooklyn Institute of Arts and Sciences) coöperating with the city. The city owns the land, has made appropriations of corporate stock for permanent improvements of the grounds and to meet part of the cost of the construction of buildings, and makes an annual appropriation in the tax budget for maintenance. The articulation with the city government is through the department of parks. The private organization has provided a permanent endowment, the income from which is supplemented by membership dues, 


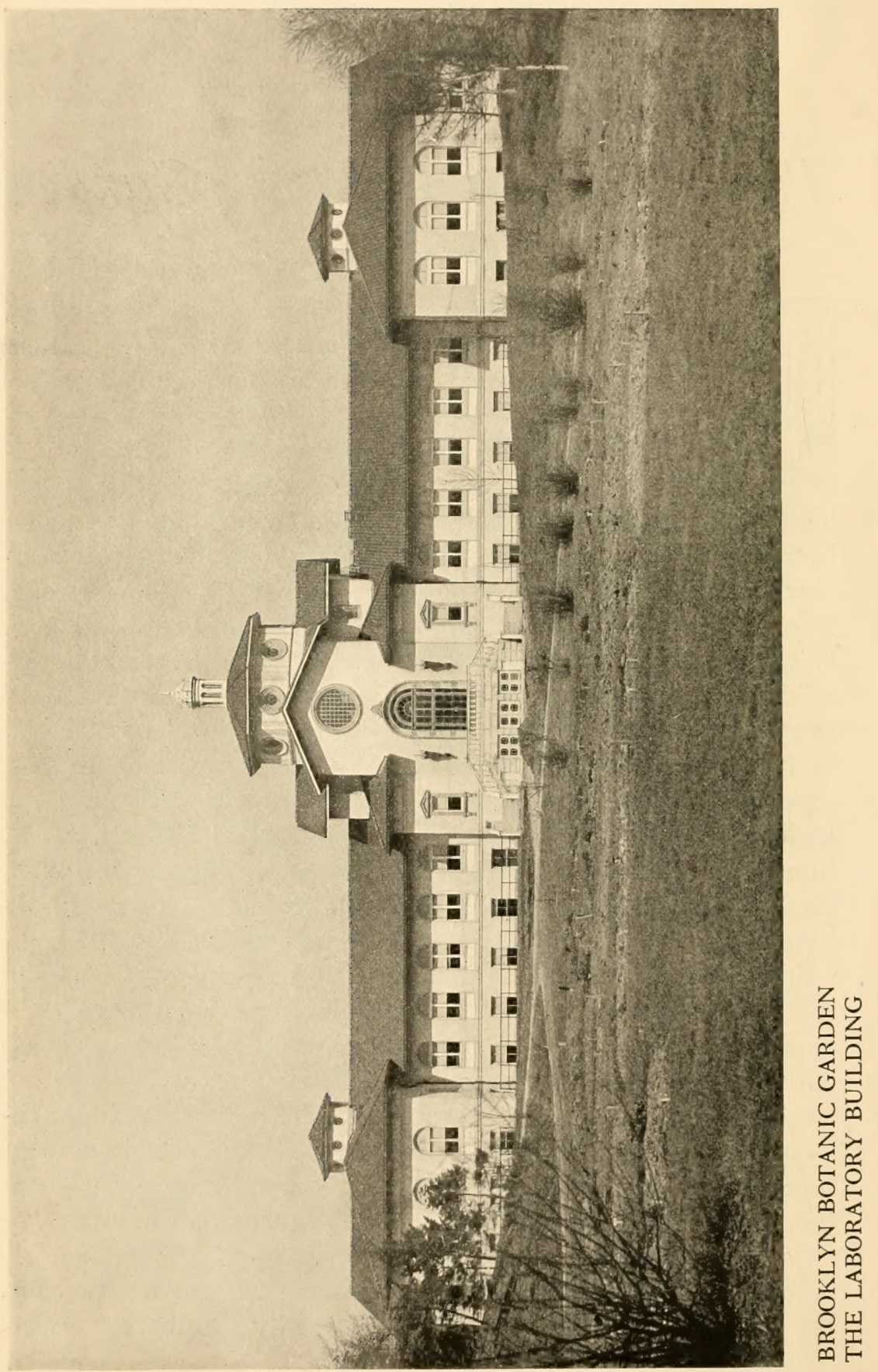


special contributions, and, to a very slight extent, by income from tuition and sales.

An institution thus supported is under a double obligation; first to the community, second to science. This obligation is recognized by the Garden in its motto, "For the advancement of botany and the service of the city," and the work is organized about these two ideas.

A botanic garden may serve the city by affording additional park space for suitable recreation, and by ministering to the aesthetic sense of the people; it should be beautiful and inviting as well as instructive. But a botanic garden is more than a park, and may render other and more valuable services, especially where there is already ample provision of park space.

The plantations of the Brooklyn Garden are laid out in eight sections as follows:

1. Systematic Section.

$a$. Hardy herbaceous plants, exclusive of local flora. arranged in beds according to their natural affinities.

b. Shrubs (Fruticetum).

c. Trees (Arboretum).

2. Local Flora Section.

Herbaceous and woody plants growing without cultivation within a radius of 100 miles of New York City.

3. Morphological Section.

a. External Anatomy.

b. Comparative Morphology.

4. Ecological Section,

Illustrating the adjustment of plants to their surroundings.

5. Evolution Section.

Illustrating various facts of Variation, Inheritance, Artificial and Natural Selection, Struggle for Existence, Survival of the Fittest, and Plant Breeding.

6. Economic Section.

a. Foods and Condiments.

$b$. Medicinal and Poisonous Plants.

c. Fiber Plants. 


\section{WeEd Section.}

Showing the characters of weeds.

8. Conventional and Formal Sections.

a. Japanese Garden.

b. Rock Garden.

c. Esplanade.

$d$. Laboratory and Conservatory plazas.

The distinctive feature of the Systematic Section is the plan to combine the fruticetum and the arboretum with the herbaceous garden. The herbaceous plants are arranged by families in beds, and the beds grouped in orders. The beds of each order are surrounded by the shrubs and trees belonging to the same order, and there is a grass aisle 30 feet wide between each two orders. In this way the botanical affinities of the herbaceous and woody plants are emphasized more clearly than is possible by the old arrangement of herbaceous garden, fruticetum, and arboretum as separate plantations.

Much careful study, and the coöperation of the landscape architect were necessary in order to perfect an arrangement like this, which could accomplish what was desired from the botanical point of view, and not do violence to the beauty of appearance. Some concessions had, of course, to be made, but on the whole the arrangement has been worked out very satisfactorily.

The Local Flora Section (or native wild flower garden, as it is popularly called), is one of our most widely appreciated features, especially by plant lovers and devotees of nature study. The plan is not alone to have one or two specimens of each species in beds, but to have large groups of each sort, such as Trillium, blood-root, wild ginger, wild geranium, Cypripedium, wintergreen, Jack-in-the-pulpit, and others.

To facilitate the growing of bog plants, which tolerate an acid soil, a small bog was brought in barrels from the pine harrens of New Jersey, and placed in a basin prepared for it in the wild flower garden. Here such plants as huckleberry, cranberry, and other bog plants find a congenial habitat.

The Brooklyn Garden has been made the depository of the 


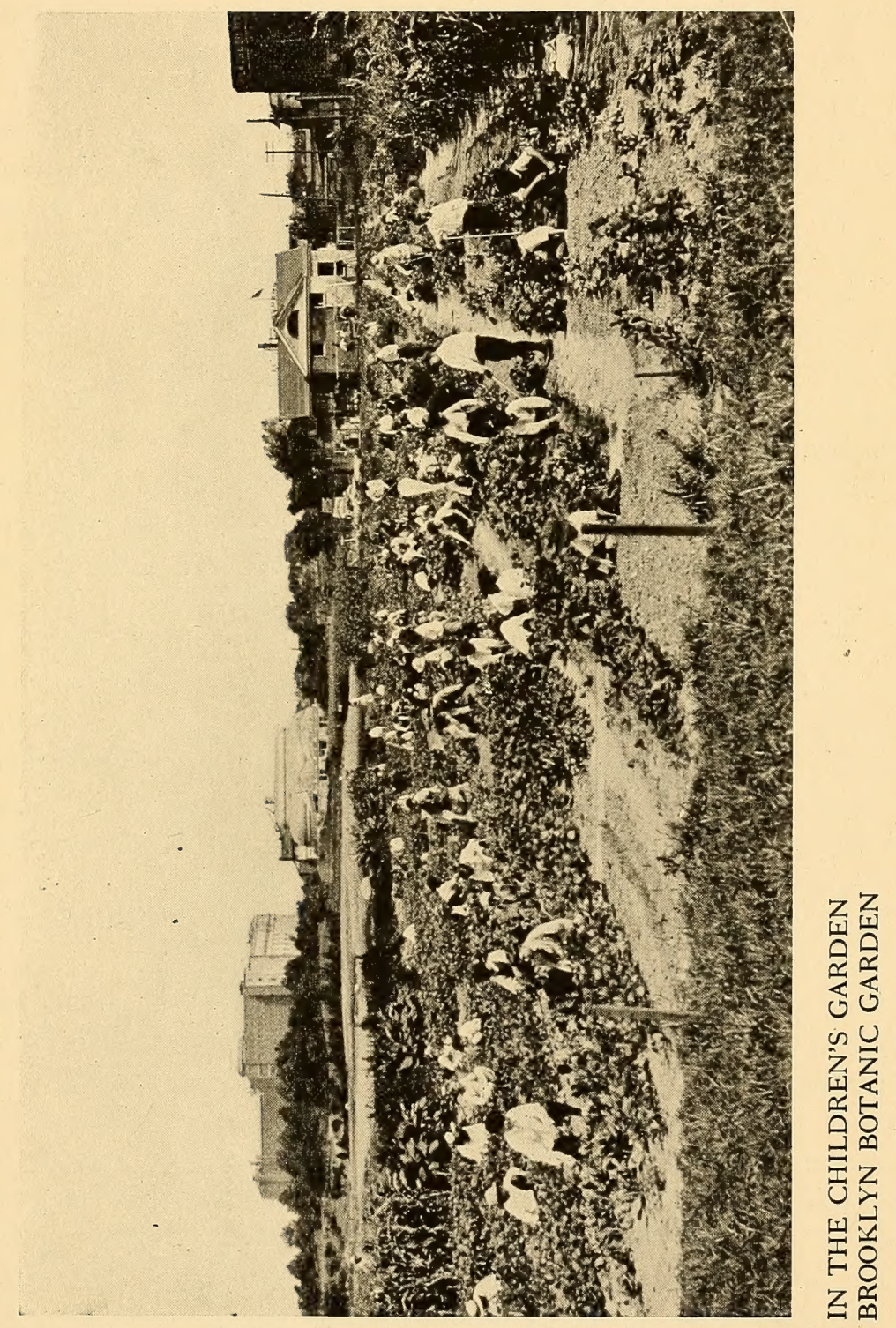


living collection of the American Fern Society, and the Fern Garden was started in the fall of 1916, at the northern end of the wild flower garden.

The violets are planted on a grassy slope with space between each species, so as to decrease the liability of mixing the species by the forcible scattering of seeds, which is characteristic of the violets.

The Ecological Section has the brook and swamp on its east side and the rock garden on the west. It is the aim of this section to illustrate the "home life" of plants, and their adjustment to various factors of environment, such as water, light, gravity, soil, insects, and other plants.

There is not space here to speak in detail of all the sections, but special mention should be made of the Japanese garden, for competent critics, both American and Japanese, have assured us that this is the most perfect example of a Japanese garden in any public park in the United States, and probably not surpassed by any in either public or private grounds in its faithful adherence to the principles of Japanese landscape gardening, and in its intrinsic beauty. The large torii like the famous one at Miyajima, Japan, stands in water, and beyond, on the slope of the hill, "heaven," is the Inari shrine. A torii always indicates an approach to a temple or shrine. The shrine is made of California redwood, and is put together entirely without nails, except for the shingles on the roof.

The garden, with its waterfalls, stone lanterns, drum bridge, formed trees, moon-view house, and other characteristic features may best be viewed from the tea house and wistaria arbor across the lake. An annual Japanese tea party, with cherry trees and azaleas in bloom, is enjoyed by the members of the Botanic Garden and their friends. The Japanese garden was a gift to the Botanic Garden, and was not only constructed but has also been partly maintained without expense to the city.

Among several special collections that are planned, only the lilac collection has been started. There are at present over 130 varieties. All plants for the Botanic Garden, not received by exchange or gift, must be purchased by private funds, and op- 


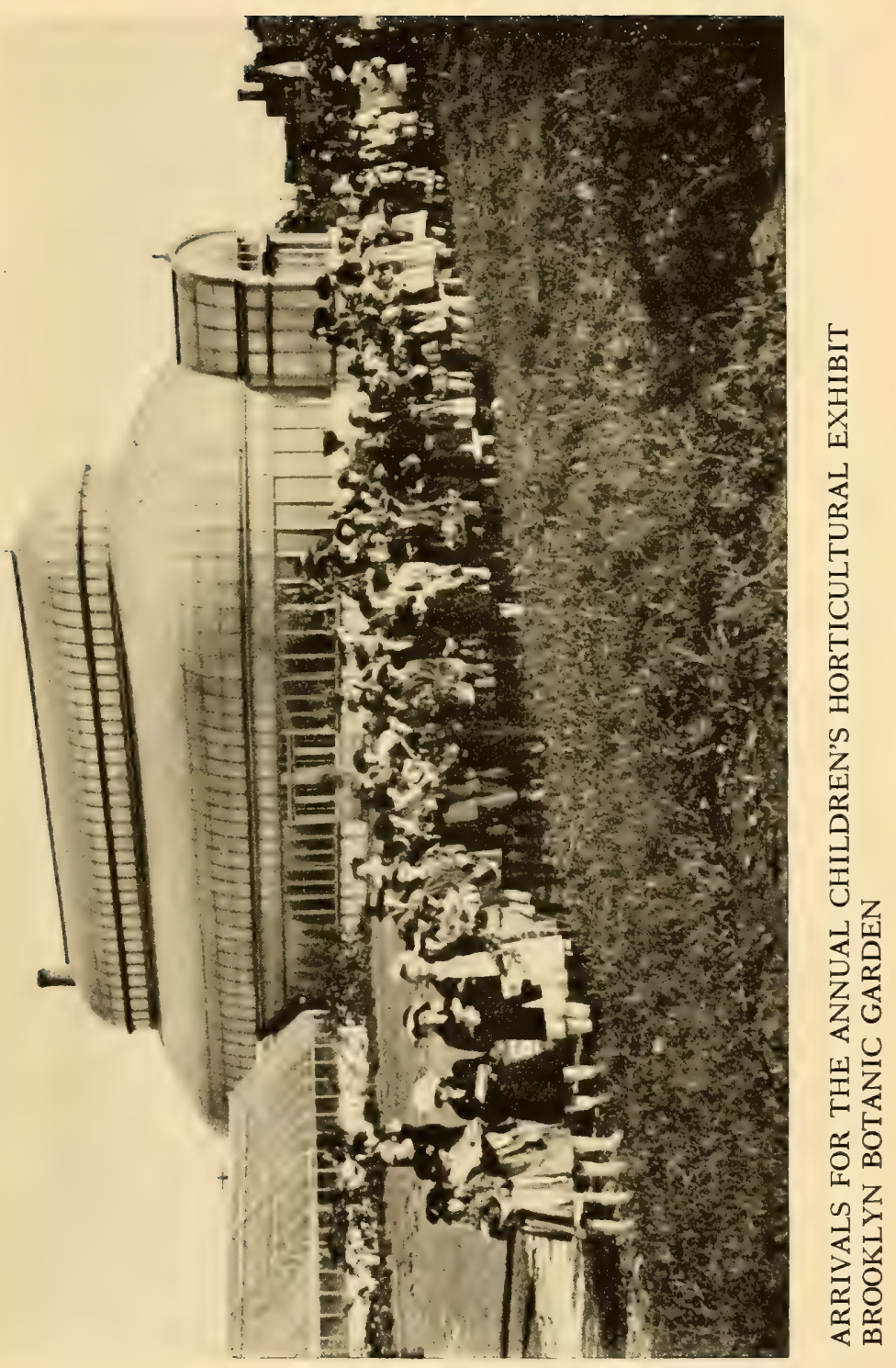




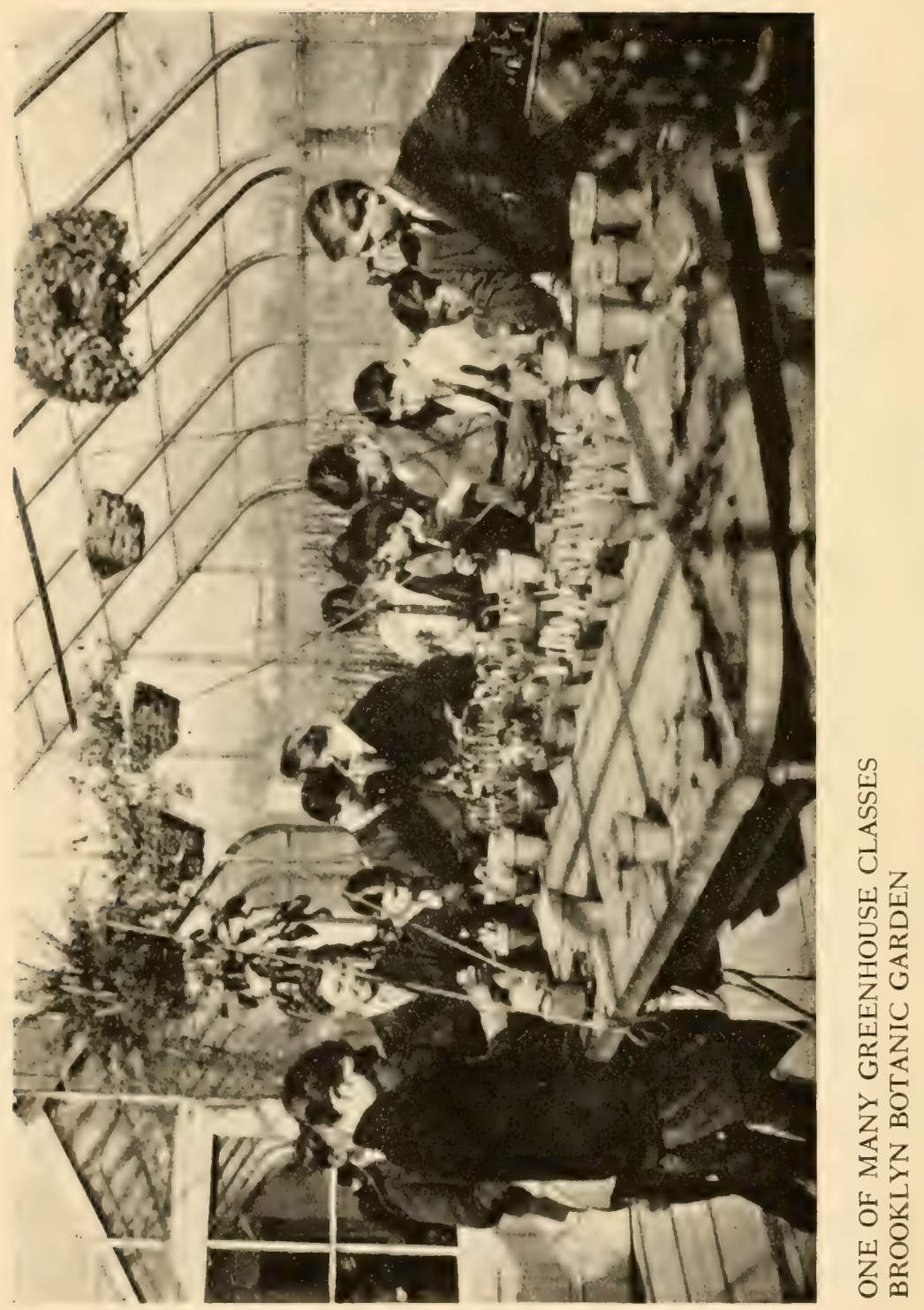


portunity is here afforded for lovers of plants and their fellowmen to render a valuable public service by making possible the installation of numerous collections such as that of the lilacs.

The distinguishing feature of the conservatories is the collection of tropical and sub-tropical economic plants. This is not only of great popular interest, but is specially appreciated by teachers of nature study and of geography in the public and private schools of the city. Here the pupils may see growing, and fruiting at the proper season, such plants as banana, orange, lemon, kumquat, citron, tea, coffee, fig, sugar cane, avocado (the so-called "alligator pear"), guava, sisal, Manila hemp, vanilla, cocoanut, chocolate tree, Para rubber plant, and numerous others that could never have been seen except by extensive travel, were it not for such a collection as this.

One can only mention here the herbarium and library, open free daily to the public, and the research work in pure and applied botany for which ample provision has been made in laboratories and private research rooms.

The Botanic Garden Leaflets, issued at weekly and bi-weekly intervals from April to October, inclusive, give popular information about plant life, and points to be seen to best advantage in the Botanic Garden near the date of issue. Current numbers of these Leaflets are at present sent free to all who wish them. The Garden also publishes a quarterly Record (the April number of which contains the annual report of the Garden), a series of scientific Contributions, a series of scientific Memoirs, and the monthly American Journal of Botany, published in cooperation with the Botanical Society of America.

Among the more popular activities of the Garden is the work with children. Numerous courses of instruction are offered throughout the year, including stereopticon lectures, practical work in the plant houses, and children's gardens. The special feature of the work with children, distinguishing it from that more usual in museums and other educational work supplemental to regular school classes, is that it emphasizes courses of instruction, as contrasted with isolated or non-related lectures. There is doubtless something of value in lecturing to 
an audience of $800-1500$ boys and girls of twelve to sixteen or eighteen years of age, but such a plan, though giving imposing figures of attendance for annual reports and newspaper articles, probably yields the smallest returns of any educational process.

As arranged at the Brooklyn Garden, children meet in small classes of from 25-30, and thus each pupil may receive individual attention from the instructor. Most of the sessions are of the nature of laboratory work-field trips and actual work in the plant house or garden.

The classes are of two kinds; those organized by the Garden, apart from schools, and school classes that come to the Botanic Garden with their teacher. In the latter case some classes come to the Garden the first period in the morning (8.30 or 9.00), going thence to their schools; others come to the Garden for the last period, going thence directly home. The Garden classes proper meet afternoons after school, and on Saturday mornings. The latter work is, of course, all purely voluntary.

Moreover, except for the school classes, every child must pay something, however nominal, for his instruction. For one course, meeting ten times, the charge is only twenty-five cents; but this is amply sufficient to secure the educatonal advantage which is the chief reason for making a charge. After having tried both plans (charging and not charging) it has been clearly demonstrated that the children are not only much more prompt and regular in their attendance, but are more certain of remaining to the end of the course, have more respect for the work, and show more zest and interest. One boy has walked as far as five miles every Saturday for several weeks, and another boy has taken a round trip journey of three hours on ferry, subway, and trolley every Saturday for more than a year. Boys do not make such efforts to "go to school" voluntarily, and in addition to regular school duties, unless they are intensely interested.

The children have voluntarily organized a Boys' Club (now having over 500 members), and a Girls' Club (having over 400 members). Certificates are awarded on the satisfactory com- 


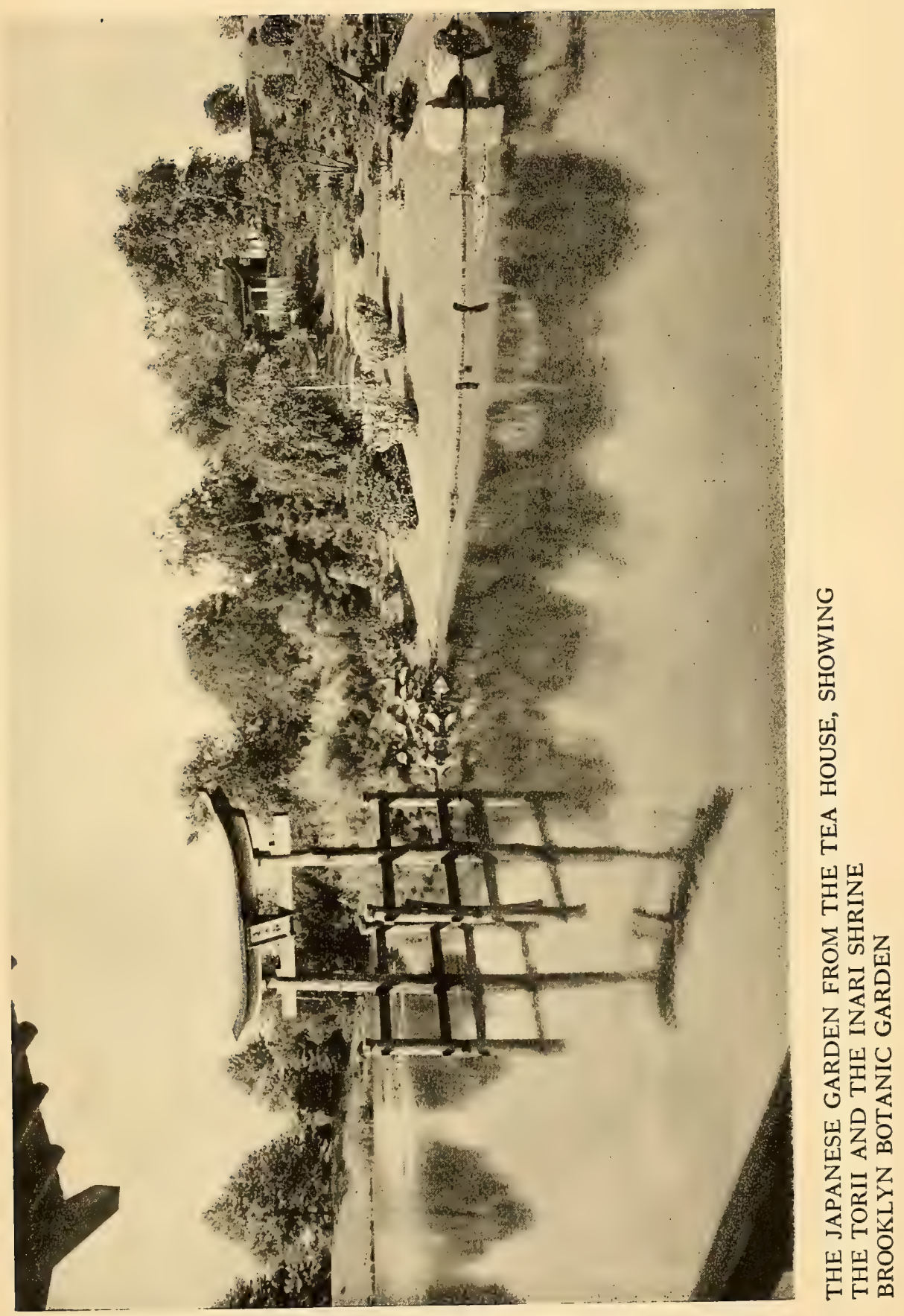




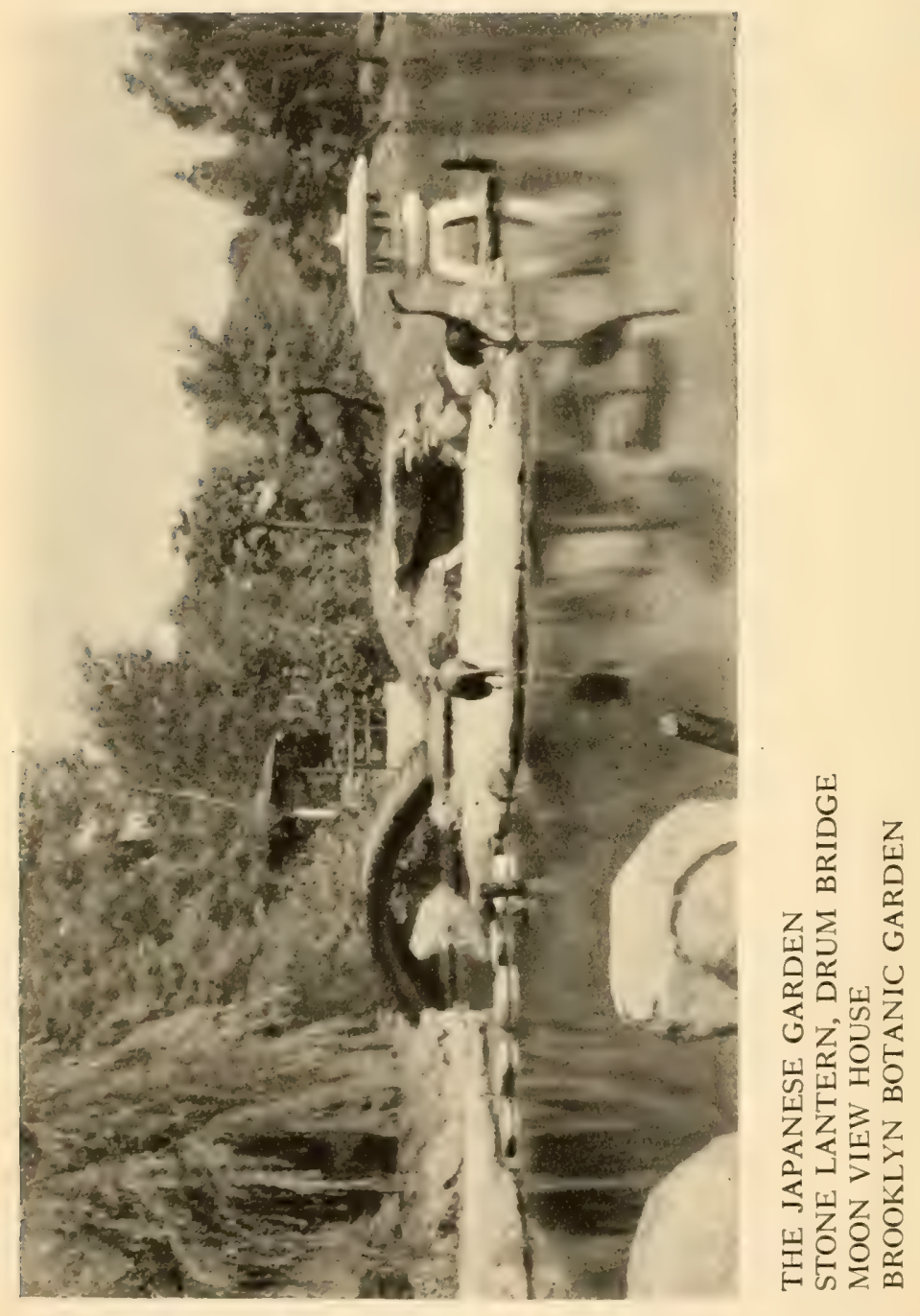


pletion of a first course, a bronze button for the second course, and a silver button for the working out of a more advanced problem.

In addition to the work at the Garden, children have, for the past four years, been supplied with penny packets of vegetable and flower seeds. The first year 25,000 were called for, this year over 115,800 . This means a great many home gardens under cultivation in the city. In the fall a Children's Horticultural Exhibit is held, and prizes are awarded to individuals and to schools.

In addition to the above work, almost the entire time of one member of staff and a portion of the time of three more is required to meet the requests for talks and lectures on nature study, plant life, and gardening at public and private schools, and before mothers' clubs, and various other organizations.

One of the greatest obstacles to satisfactory work in children's gardens has been the lack of adequately trained teachers, and opportunities to secure thorough preparation are not numerous. An interest in children, a mere liking for the work, or even native teaching ability, while highly essential, are not, of themselves, sufficient to insure success. Facing this situation the Botanic Garden organized a course for the preparation of teachers of gardening. The work was planned to extend through the entire year, so that an opportunity would be afforded to get first hand experience in the garden operations of each season. The course includes both theory and practice with sub-courses in soils and agricultural principles, elementary botany, nature study, fungous and insect pests of the garden, pedagogy, genetics, woodwork, plant propagation, and greenhouse work. Each teacher in training must plant a garden and carry it through every operation to the harvesting of a crop, doing herself everything she will be expected to teach her future pupils. Furthermore she must do actual teaching in the garden and greenhouse under the supervision of a critic teacher. Before the final certificate is awarded, each teacher must put in a summer's work with children in the Botanic Garden under supervision. 
During the present unusual situation brought about by the war the Garden has provided, free of cost, the services of an expert gardener to inspect vacant lots throughout Brooklyn, and to some extent in adjacent boroughs of Greater New York, to give instruction in gardening to individuals and neighborhood groups, and to supervise vacant lot gardens through the summer until the crop is harvested.

The Garden has also published two Leaflets, one on "The small vegetable garden," and one on "Insect Pests." These are distributed free to all who wish them. In addition, the Garden has served as the center of distribution of seed potatoes in Brooklyn for Mayor Mitchel's Food Committee, and nearly 200 bushels have been thus supplied for the planting of vacant lot gardens.

In closing, the writer wishes to urge the desirability of the establishment of botanic gardens in all American cities having a population of from 5,000 to 10,000 or more. This is "another story," and can only be mentioned here, but after the war is over, and men's minds can be turned once more to the occupations of peace, a nation wide movement should be started for the establishment of botanic gardens. 




\section{QK73.B74 G33}

Gager Charles Stua/The Brooklyn Botanic

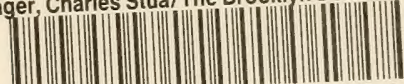

35185001131091 

